\title{
Experimental bilateral lobar lung transplantation and its application in humans
}

\author{
J P Couetil, M J Tolan, A Grousset, D Benaim, M Sapoval, A Hernigou, P Coppens, \\ P Fayolle, A Carpentier
}

\begin{abstract}
Background - The critical lack of donor organs from people of small size or children has created great difficulties in transplantation for recipients who are of smaller size. Surgical techniques of organ reduction and partial transplantation may to some extent solve the problem of disparity in organ size, be it liver or lung, and lessen the problem of scarcity of paediatric organs.
\end{abstract}

Methods - In a series of experiments on dogs the surgical technique of pulmonary partition of a large organ from a grown dog followed by transplantation of lobes, either unilaterally or bilaterally, into a young dog was studied. Two series of experiments were performed in two groups of animals; in group 1 transplantation of a single right lobe $(n=6)$ or single left lobe $(n=6)$ from a split adult lung was carried out and in group $2(n=10)$ animals received bilateral lobar transplants from a single split adult lung. The animals were sacrificed at fixed intervals (days 8-120 in group 1, days 7-10 in group 2) and the results of the surgical technique were assessed.

Results - Healing of lobar bronchial anastomoses was found to be excellent with no histological evidence of dehiscence or ulceration. There was one bronchial anastomotic stenosis and one arterial thrombosis. Morphological and functional adaptation of the lobes in the thorax was found to be excellent in both groups of animals. The technique has been applied in a clinical setting and the first patient with bilateral lobar lung transplantation followed for $\mathbf{3 0}$ months is reported.

Conclusion - Lung partition and subsequent lobar transplantation, either unilaterally or bilaterally, is associated with satisfactory early results in an animal experience in one patient has been successful.

(Thorax 1997;52:714-717)

Keywords: pulmonary lobar transplantation, pulmonary splitting, experimental study.

Correspondence to: Dr M J Tolan, University Hospital, Tremona Road, Southampton SO9 4XY, UK.

Received 28 June 1995 Returned to authors 20 November 1995 Revised version received 27 January 1997 Accepted for publication 15 April 1997

Pulmonary transplantation faces the immense problem of lack of donors and increasing numbers of patients for transplantation. ${ }^{1}$ The scarcity of organs has considerably limited the number of operations performed. This is parperimental model. Initial clinical ex-

ticularly relevant in the case of children or adults of small size, and especially when bilateral transplantation is required.

Recent studies of transplantation of pulmonary lobes in animals ${ }^{2-6}$ have been successful at medium term follow up with respect to haemodynamics and equitation of volume and conformity of the lobes in the thorax of the recipient. Satisfactory results of pulmonary reduction and lobar transplantation, ${ }^{7}$ and liver bipartition from either cadaveric ${ }^{89}$ or living donors ${ }^{1011}$ are reported clinically. In this study we have examined a method of bilateral transplantation with one large lung divided into two implantable lobes. Using adult dogs as donors, single lungs were divided into separate lobes and implanted unilaterally and bilaterally into young dogs.

\section{Methods}

The Labrador dog was chosen as the animal model having the most favourable anatomical and morphological features. ${ }^{12}$ It has complete interlobar fissures which greatly facilitates separation of lobes and lessens morbidity due to air leakage. Adult Labrador dogs $(22-35 \mathrm{~kg})$ or pups $(8-11 \mathrm{~kg})$ are of sufficient size to permit use of standard clinical techniques of transplantation. The various operative protocols were reviewed and approved by the Veterinary Ethics Committee and conformed to the principles of utilisation of animals in the laboratory as formulated by the National Society for Medical Research published by the National Institute of Health (NIH publication no. 85-23, revised 1985).

Twenty two labrador pups aged 2.5-4 months and weighing $4-11 \mathrm{~kg}$ were divided into two groups. In group 112 pups were transplanted unilaterally, six on the right with either the right apical middle lobes or right lower lobe of the adult donor and six on the left with either the left apical middle lobe or the left lower lobe of the same adult lung. The second group comprised 10 pups transplanted bilaterally with the donor left apical middle lobe implanted on the left and the donor left lower lobe implanted on the right.

\section{PROCEDURE}

\section{Donor operation}

After placing a cephalic vein catheter, each dog was premedicated with glycopyrolate $0.01 \mathrm{mg} /$ $\mathrm{kg}$ intravenously and diazepam $0.03 \mathrm{mg}$. Anaesthesia was induced with sodium thiopentone $10 \mathrm{mg} / \mathrm{kg}$ intravenously and maintained with 

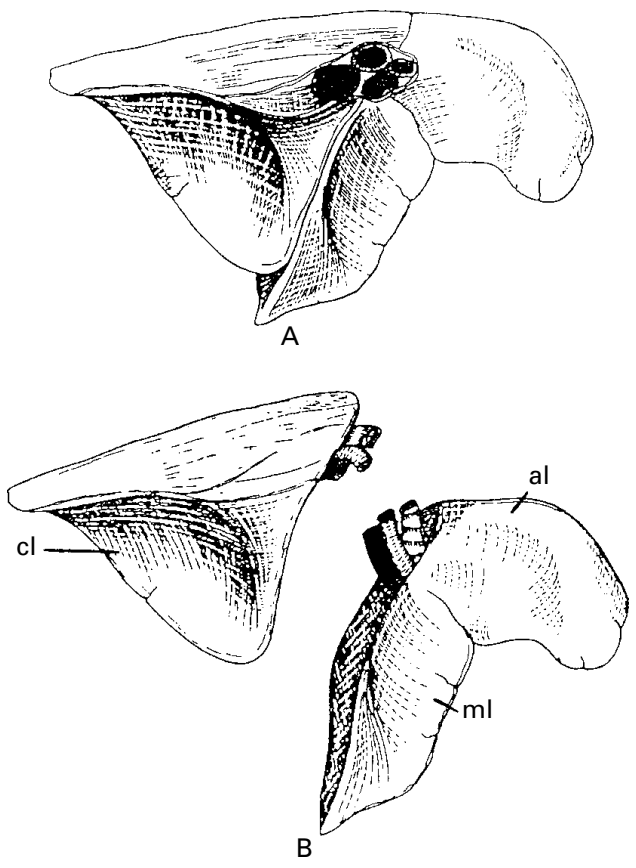

Figure 1 Splitting of the left lung. (A) Intact left lung. (B) Lower (caudal) lobe (cl) and upper (apical) and middle lobes (al, $\mathrm{ml})$ are separated.

isoflurane and oxygen on mechanical ventilation. In the donor operation removal of the right or left lung was by standard technique via a lateral thoracotomy in the fifth intercostal space. After the first pneumonectomy the animal was revived so that the contralateral lung could be used for donation at a later stage. Explanted lung preservation was ensured by immediate instillation of pneumoplegia $(500 \mathrm{ml}$ crystalloid Eurocollin's modified solution at $8^{\circ} \mathrm{C}$ ). The lung was maintained insufflated in a solution of Eurocollin's at $8^{\circ} \mathrm{C}$.

\section{Recipient operation}

The recipients were anaesthetised using a similar protocol. Muscle relaxation was obtained with pancuronium $0.02 \mathrm{mg} / \mathrm{kg}$ i.v. Continuous blood pressure monitoring was by Doppler ultrasound of the radial artery. Oxygen and carbon dioxide levels were continuously monitored by capnography. At the end of the operation an analgesic (buprenorphine $0.006 \mathrm{mg} /$ $\mathrm{kg}$ ) was given to allow immediate extubation.

\section{Technique of lung partition}

The separation of lobes was relatively simple and quickly performed on the left (fig 1) but was more complex on the right due to incomplete separation of fissures and a more complex vascular network. Separation was achieved just prior to their implantation in the recipient. The fissures having been completed, intrahilar dissection of the pedicle was necessary. On the left it started with separation of the veins, establishing drainage of the lower and apical middle lobes. The dissection and separation of the lobar bronchi was done by opening the bronchial stump and dividing down into each lobar bronchus. The stump was then resected. The pulmonary artery was divided obliquely in the fissure. This division meant that, in effect, two orifices of the upper pulmonary artery were generated. The main or proximal orifice was sutured closed and the fissural orifice was used for anastomosis to the recipient pulmonary artery. On the right the same principal steps were followed as the left but separation at the hilum was much more difficult because of the more complex pulmonary arterial branching. It was necessary to excise the accessory lobe to facilitate the donor operation.

\section{Implantation of pulmonary lobes}

An extrapericardial pneumonectomy was performed via a left or right thoracotomy in the fifth intercostal space. The donor lobe was introduced into the thoracic cavity and the anastomoses fashioned - the vein, followed by the artery, followed by the bronchus, using polypropylene $7 / 0$ throughout. All anastomoses were easily aligned except for the placement of the left apical middle lobe on the right. The bronchus was well aligned as was the vein but the proximal end of the pulmonary artery was on the opposite side of the bronchus to the recipient pulmonary artery. The anastomosis was facilitated by anastomosing the fissural orifice of the donor pulmonary artery after further dissection in the hilum of both the donor and recipient. Implantation of the left lower lobe on the right necessitated an endto-side bronchial anastomosis to the recipient apical bronchus. On the left the implantation of the apical middle lobe did not present any difficulty. The animal was heparinised (100 U/ $\mathrm{kg}$ i.v.) immediately before removing the vascular clamps. After completion of the operation and expansion of the lobes, the thoracic cavity was completely filled by the right or left apical middle lobes implanted on the right or left, respectively, but incompletely filled by lower lobes leaving unoccupied space in the thorax. In the bilaterally transplanted dogs the accessory lobes and right lower lobes of the recipient were left in place to preserve the HerringBreuer reflex for control of respiration. ${ }^{12}$ Thus, the right pneumonectomy was incomplete.

\section{Immunosuppression}

All animals received cyclosporin $5 \mathrm{mg} / \mathrm{kg}$ i.m. twice daily until the end of the protocol and methylprednisolone $200 \mathrm{mg}$ i.v. initially and $5 \mathrm{mg} / \mathrm{kg}$ i.m. for the first 10 days. Acute rejection was diagnosed clinically (tachycardia, fever, lethargy, nasal discharge) and radiologically (perihilar opacities). Each episode of rejection was treated empirically with boluses of methylprednisolone $500 \mathrm{mg}$ i.m. for three days.

\section{Postoperative evaluation}

Daily chest radiography was performed for the first three days and when indicated thereafter. Echocardiography and pulmonary angiography 


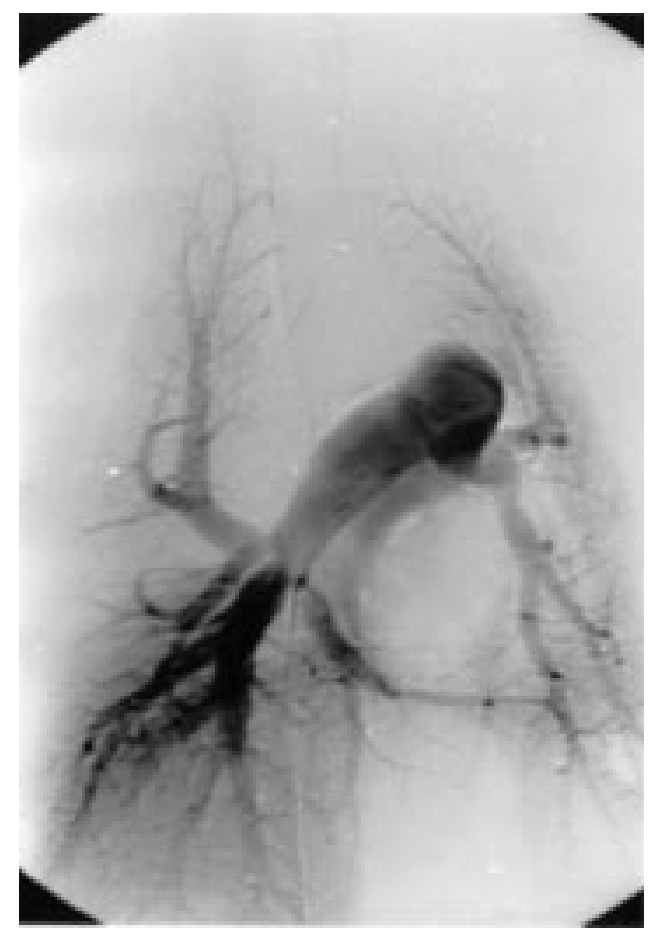

Figure 2 Pulmonary angiogram of the left lower lobe on the right and the left upper middle lobe on the left after transplantation.

(fig 2) were performed just before the animals were sacrificed. A post-mortem examination was performed on all animals with pathological evaluation of the transplants. The animals in group 1 were sacrificed according to a time scale which allowed medium term study of the growth of transplanted mature lobes in growing animals. The animals in group 2 were sacrificed on day 10. No respiratory function studies were done.

Table 1 Group 1: recipients of right or left single lobes

\begin{tabular}{|c|c|c|c|c|c|}
\hline \multirow[t]{2}{*}{ Recipients } & \multicolumn{2}{|l|}{ Survival } & \multicolumn{2}{|c|}{ Complications } & \multirow[b]{2}{*}{ Lobes transplanted } \\
\hline & Day of death & Day of sacrifice & Rejection & Infection & \\
\hline 1 & 0 & & & & L-UML \\
\hline 2 & & 8 & + & - & L-LL \\
\hline 3 & & 11 & + & + & R-LL \\
\hline 4 & & 60 & + & - & R-UML \\
\hline 5 & 0 & & - & - & R-LL \\
\hline 6 & & 120 & + & + & R-LL \\
\hline 8 & 4 & & + & - & L-UML \\
\hline 9 & 25 & & + & + & R-LL \\
\hline 10 & 4 & & + & - & R-UML \\
\hline 11 & & 130 & + & + & L-LL \\
\hline 12 & & 120 & + & + & L-UML \\
\hline
\end{tabular}

$\mathrm{R}-\mathrm{LL}=$ right lower lobe; $\mathrm{R}-\mathrm{UML}=$ right upper/middle lobe; $\mathrm{L}-\mathrm{UML}=$ left upper/middle lobe; $\mathrm{L}-\mathrm{LL}=$ left lower lobe.

Table 2 Group 2: recipients of bilateral lobar implants from a single donor lung

\begin{tabular}{|c|c|c|c|c|c|}
\hline \multirow[t]{2}{*}{ Recipients } & \multicolumn{2}{|l|}{ Survival } & \multicolumn{2}{|c|}{ Complications } & \multirow{2}{*}{$\begin{array}{l}\text { Post-mortem } \\
\text { examination of } \\
\text { hilum }\end{array}$} \\
\hline & Day of death & Day of sacrifice & Rejection & Infection & \\
\hline 1 & 0 & & & & \\
\hline 2 & & 10 & + & + & Normal \\
\hline 3 & & 8 & + & - & Normal \\
\hline 4 & & 7 & - & + & Normal \\
\hline 5 & 5 & & + & + & Normal \\
\hline 6 & & 7 & + & - & Normal \\
\hline 7 & 7 & & + & $\stackrel{+}{\text { (peritonitis) }}$ & Normal \\
\hline 8 & & 8 & + & - & Normal \\
\hline 9 & & 1 & - & - & $\begin{array}{l}\text { Thrombosis of } \\
\text { pulmonary artery }\end{array}$ \\
\hline 10 & 0 & & & & \\
\hline
\end{tabular}

\section{Results}

GROUP 1

Two animals died perioperatively, one of haemorrhage and the other following prolonged ventricular fibrillation. All survivors had one or more episodes of acute rejection. At post-mortem examination five dogs had evidence of acute rejection and pulmonary infection caused death in three cases (table 1). The anastomotic suture lines were all satisfactorily healed in the 10 dogs examined histologically with no evidence of dehiscence or residual ulceration. Only one bronchus was stenosed of 20 that were at risk. Five of the dogs that survived longer (60-150 days) had CT scans before being sacrificed and in all developing lesions of chronic rejection were seen. Planar imaging gave excellent images in three cases and somewhat less clear in two, but all lobes appeared to be perfectly adapted to the morphology of the recipient thorax.

\section{GROUP 2}

Mean ischaemic times for the first side transplanted were 120 (15) minutes and 180 (20) minutes for the second side. Two dogs died perioperatively, one due to hypoxia during contralateral transplantation and the second due to prolonged ventricular fibrillation. Two dogs died at days 5 and 7, one of viral gastroenteritis (kennel epidemic), the other of perforated gastric ulcer after having three courses of steroids for rejection. Pathological results are summarised in table 2 . Of the eight recipients examined one artery was thrombosed causing massive pulmonary infarction. The thrombosis was due to a malpositioning of an end-to-end anastomosis of a left lower lobe implanted in a right apex. All other anastomoses were satisfactory.

\section{Discussion}

Paediatric lung transplantation, as well as that of adults of small stature, is particularly limited by a scarcity of donor organs. With the hope of expanding the possibilities for transplantation, techniques of pulmonary reduction and lobar transplantation from either live donors or cadaveric donors have been developed..$^{71013}$ These techniques, while increasing paediatric transplantation numbers, still lead to some wastage of organs with loss of one or several non-transplanted lobes.

Partition of the lung is one approach that resolves the discrepancy in size between donor and recipient and maximises the use of available organs. This technique has been used with success in liver transplantation ${ }^{8913}$ and allows two children to be transplanted with one liver. Using the techniques described in this paper, it would now be possible to separate one large donor lung into two lobes and implant these bilaterally in a child. The second donor lung could be used in a second recipient.

Separation of the lobes of the lung is easily achieved in the dog model as the interlobar fissures are complete. ${ }^{14-16}$ The creation of a transplantable pedicle is also easily done. ${ }^{17} \mathrm{Sev}$ - 
eral technical points require elaboration, however. In the recipient it is essential that sufficient length of vascular and bronchial pedicle are left to avoid any anastomotic tension. Care must be taken in positioning the donor lobe in the thorax prior to anastomosing the vessels so that there is no undue tension when ventilation is restored. In one case in this experimental series malposition of a lobe caused twisting of an arterial suture line and massive infarction of the lobe. The quality of bronchial healing was remarkably good in this series. Several studies suggest that the technique of telescoping the anastomosis favours healing. Although we used an end-to-end technique a certain amount of telescoping invariably occurs. In contralateral transplantation of lobes the rotation of the bronchus necessitated anastomosis of the muscularis portion to the collagenous ring portion and vice versa. This did not cause any problem with bronchial healing. Our results also confirm that the more distal the bronchial anastomosis the better the healing. ${ }^{18}$ Maintaining endothelial continuity in the vessel or endocardium lessens the risk of pulmonary venous thromboses postoperatively.

In conclusion, we have shown that the technique of lobar separation followed by bilateral transplantation gives satisfactory results in an animal experimental model. Further longer term animal and clinical studies are required to assess the full potential of this technique in increasing the number of lung transplantations in children and adults of short stature.

\section{Addendum}

Following the success of these animal experiments the technique was applied clinically for the first time in May 1993. The recipient was a patient aged 40 years $(40 \mathrm{~kg}, 150 \mathrm{~cm})$ with chronic respiratory failure. The left lung of a much larger donor $(80 \mathrm{~kg}, 180 \mathrm{~cm})$ was divided into upper and lower lobes. The left lower lobe was transplanted into the left thorax of the recipient and did not present any difficulty as the alignment was anatomical. Implanting the left upper lobe on the right after a $180^{\circ}$ rotation presented the fissural orifice of the pulmonary artery exactly aligned with the recipient pulmonary artery, thus avoiding the difficult anastomosis that would have resulted had the proximal orifice of the pulmonary artery been chosen.

The patient made an uncomplicated recovery and, despite two episodes of rejection, he remains well with satisfactory chest radiological appearances and good pulmonary function: (forced vital capacity 1.911 (71\% predicted); forced expiratory volume in one second 1.831 $(81 \%)$; total lung capacity $3.061(75 \%)$.

1 Couetil JP, Scott JP, Serrano-Fiz S, Higenbottam TW, Wallwork J. Transplantation cardiopulmonaire: experience de Cambridge. Coeur 1989;20:209-13.

2 Spray TL, Mallory GB, Cantter CB, Huddleston CB. Paediatric lung transplantation: indications, techniques, and early results. F Thorac Cardiovasc Surg 1994;107:990-1000

3 Bismuth H, Houssin D. Reduced size orthoptic liver grafts in hepatic transplantation in children. Surgery 1984;95 367-70.

4 Lillehei CW, Everts E, Shamberger RC. Reduced size lung transplantation from adult to neonatal sheep. $\mathcal{F}$ Paediat Surg 1992;27:1153-6.

5 Cromblehome TM, Adzick NS, Longaker MT. Reduced size lung transplantation in neonatal swine: technique and short-term physiologic response. Ann Thorac Surg 1990; 49:55-60.

6 Haverich A, Darnmenhayn L, Demertzis S, Kemnitz J, Reimers P. Lung growth after experimental pulmonary Reimers P. Lung growth after experimental pulmonary

7 Hislop AA, Odom NJ, McGregor CG, Haworth SG. Growth potential of the immature transplanted lung. An experimental study. F Thorac Cardiovasc Surg 1990;100:360 70

8 Huggins E. Reimplantation of lobes of the lung: an experimental technique. Lancet 1959;ii:1059-61.

9 Otte JB, de Ville de Goyet J, Sokal E, et al. Size reduction of the donor liver is a safe way to alleviate the shortage of size-matched organs in paediatric liver transplantation. Ann Surg 1990;211:146-57.

10 Starnes VA, Barr ML, Cohen RG. Lobar implantation: indications, techniques and outcome. $\mathcal{F}$ Thorac Cardiovas Surg 1994;108:403-11.

11 Strong RW, Lynch SW, Ong TH, Matsunami H, Koidy L, Balderson G. Successful liver transplantation from a living donor to her son. N Engl f Med 1990;322:1505-7.

12 Backer CL, Ohtake S, Zales VR. Living related lobar lung transplantation in beagle puppies. F Paediatr Surg 1991; 26:429-33.

13 Cohen RG, Barr ML, Schenkel FA, DeMeester TR, Wells WJ, Starnes VA. Living related donor lobectomy for bilateral lobar transplantation in patients with cystic fibrosis. Ann Thorac Surg 1994;57:1423-8.

14 Pasque MK, Cooper JD, Kaiser LR, Haydock DA, Triantafillou A, Trulock EP. Improved technique for bilateral lung transplantation: rationale and initial clinical experience. Ann Thorac Surg 1990;49:785-91.

15 Otte JB, de Ville de Goet J, de Hemptinne B, et al. The concept and technique of the split liver in clinical transplantation. Surgery 1990;107:605-12.

16 Kern JA, Tribble CG, Zografakis JG, Cassada DC, Chan $\mathrm{BB}$, Kron IL. Analysis of airway function of immature whole lung transplants versus mature lobar transplants. Ann Thorac Surg 1994;57:1089-94.

17 Kern JA, Tribble CG, Flanagan TL, Chan BB, Cassada DC, Kron IL. Growth potential of porcine reduced-size mature pulmonary lobar transplants. F Thorac Cardiovasc Surg 1992;104:1329-32.

18 Kern JA, Tribble CG, Chan BK, Flanagan TL, Kron TL. Reduced-size porcine lung transplantation: long-term Reduced-size porcine lung transplantation: long-term
studies of pulmonary vascular resistance. Ann Thorac Surg 1992;53:583-9. 